\title{
Splenic Marginal Zone Lymphoma
}

National Cancer Institute

\section{Source}

National Cancer Institute. Splenic Marginal Zone Lymphoma. NCI Thesaurus. Code C4663.

A B-cell non-Hodgkin lymphoma composed of small lymphocytes which surround and replace the splenic white pulp germinal centers. It involves the spleen and splenic hilar lymph nodes, bone marrow, and often the peripheral blood. When lymphoma cells are present in the peripheral blood, they are usually, but not always, characterized by the presence of short polar villi. (WHO) 